\title{
PRODUÇÃO E PADRONIZAÇÃO DE UM ANTÍGENO PARA UM TESTE ELISA INDIRETO NO DIAGNÓSTICO DA LINFADENITE CASEOSA EM SOROS CAPRINOS
}

\author{
Production and Standardization of an Antigen Towards an Indirect ELISA \\ Test for the Diagnostic Goats Serum of Caseous Lymphadenitis
}

\begin{tabular}{|c|}
\hline $\begin{array}{l}\text { Juliano Zerbinati } \\
\text { Graduando de Medicina Veterinária UNIME, Lauro de Freitas - BA. } \\
\text { e-mail: julianozerbinati@hotmail.com }\end{array}$ \\
\hline $\begin{array}{l}\text { Iuri Coelho Greve } \\
\text { Graduando de Medicina Veterinária UNIME, Lauro de Freitas - BA. } \\
\text { e-mail: iurigreve@yahoo.com.br }\end{array}$ \\
\hline $\begin{array}{l}\text { Renata Franco Leal } \\
\text { Graduanda de Medicina Veterinária UNIME, Salvador - BA. } \\
\text { e-mail: renata_115@hotmail.com }\end{array}$ \\
\hline $\begin{array}{l}\text { Luciane Mari Prado Vasconcelos de Amorin } \\
\text { Graduanda de Medicina Veterinária UNIME, Camaçari - BA. } \\
\text { e-mail: lucianepradoamorin@yahoo.com.br }\end{array}$ \\
\hline $\begin{array}{c}\text { Diógenis Lima da Silva } \\
\text { Auxiliar de Saúde do Laboratório de Doenças Infecciosas da UNIME/LADI, Salvador - BA. } \\
\text { e-mail: diogenisls@hotmail.com }\end{array}$ \\
\hline $\begin{array}{l}\text { Simone Rosa Assis de Aquino Viegas } \\
\text { Médica Veterinária, M. Sc., Prof.a da UFBA, Salvador - BA. } \\
\text { e-mail: simone@ufBA.br }\end{array}$ \\
\hline $\begin{array}{l}\text { Ana Paula Cardoso Peixoto } \\
\text { Médica Veterinária, M. Sc., Prof. }{ }^{a} \text { da UFBA, Lauro de Freitas - BA. } \\
\text { e-mail: paulapeixoto.hosvet@unime.com.br }\end{array}$ \\
\hline $\begin{array}{l}\text { Renato Carminati } \\
\text { Médico Veterinário, M. Sc., Prof. da UNIME, Lauro de Freitas - BA. } \\
\text { e-mail: rcarminat@gmail.com }\end{array}$ \\
\hline $\begin{array}{l}\text { Robson Bahia Cerqueira } \\
\text { Médico Veterinário, M. Sc., Prof. da UNIME, Lauro de Freitas - BA. } \\
\text { e-mail: robsonba@gmail.com }\end{array}$ \\
\hline
\end{tabular}

Rev. Acad., Curitiba, v. 5, n. 3, p. 285-293, jul./set. 2007 


\title{
Resumo
}

A Linfadenite Caseosa - LC, pseudotuberculose, ou mal do caroço dos caprinos e ovinos, é uma doença infecto-contagiosa crônica, que tem como agente causador o Corynebacterium pseudotuberculosis, caracterizada pela formação de abscedação de linfonodos, tanto superficiais quanto internos, o que leva à lesão em órgãos e debilidade progressiva do animal, acarretando em diminuição da produção de leite, perda de peso e condenação de carcaça. No nordeste do Brasil há uma predominância da enfermidade em caprinos, por se tratar de uma região onde a caprinocultura tem sido utilizada como forma de subsistência para pequenos produtores. O objetivo deste trabalho foi produzir um antígeno, denominado de BMD, e padronizar um teste ELISA indireto para o diagnóstico da LC em soros caprinos naturalmente infectados e não infectados. O estudo da sensibilidade e especificidade foi verificado por análise estatística na qual se obteve resultados de 99,8\% e 98,0\% para o ELISA indireto BMD e sensibilidade, respectivamente, e especificidade de $98,0 \%$ para o ELISA indireto, utilizando o antígeno BHI.

Palavras-chave: Antígeno; Corynebacterium pseudotuberculosis; Caprino; ELISA; padronização.

\begin{abstract}
Abstact
Caseous lymphadenitis, pseudotuberculosis or Kernel (pit) disease from goats and ovines is a chronic infectcontagious disease caused by Corvuebacterium pseudotuberculosis. As a consequence, there was the formation of abscesses in both internal and superficial lymph nods generating lesions at the organs and progressive animal weakness bringing no decrease in milk production, lost of weight and carcass condenation. At the Northeast of Brazil, occurs a predominance of this disease, just in a region where the raising of goats is used as the way of subsistence for small farmers. The aim of the present research is the production of an antigen, BMD and the standardization of an indirect ELISA test for the diagnostic of caseous lynphadenitis in serum from naturally infected and non infected goats. The sensitivity and specificity results were checked by statistical analysis with the results of $99.8 \%$ and $98.0 \%$, for BMD indirect ELISA and sensitivity, respectively, and specificity of $98.0 \%$ for ELISA using the BHI antigen.
\end{abstract}

Keywords: Antigen; Corynebacterium pseudotuberculosis; Goats; ELISA indirect.

\section{INTRODUÇÃO}

A Linfadenite Caseosa, pseudotuberculosis, ou mal do caroço dos caprinos e ovinos é uma enfermidade causada pelo Corynebacterium pseudotuberculosis, de acordo com Nozaki, Faria e Machado (2000), caracterizada pelo comprometimento de linfonodos superficiais ou profundos com material necrótico de cor esbranquiçada, segundo Ayers (1977), e lesões em vísceras, conforme Cameron e Minnar (1969). Várias tentativas têm sido realizadas no sentido de elaboração de uma vacina contra a linfadenite caseosa que induza significativa imunoproteção. Contudo, os resultados têm sido pouco consistentes atribuídos a antígenos como a bactéria inteira, viva ou morta, parede celular e o toxóide obtidos a partir da exotoxina (CAMERON; FULS, 1973). Dercksen et al. (2000) relatam que os ensaios imunoenzimáticos (ELISA) apresentam boa sensibilidade para a detecção da infecção em caprinos e ovinos por Corynebacterium pseudotuberculosis. O objetivo deste trabalho foi produzir um antígeno denominado de BMD e padronizar um teste ELISA indireto para o diagnóstico da linfadenite caseosa, com a utilização de soros caprinos de animais naturalmente infectados e não infectados, avaliando a sensibilidade e especificidade frente a outro antígeno denominado de BHI. 


\section{MATERIAIS E MÉTODOS}

Foram utilizadas amostras de soro, bem como material caseoso, de caprinos acometidos ou não pela linfadenite caseosa. As amostras foram coletadas de 60 caprinos, SRD, idades variadas e provenientes de uma região endêmica do sertão da Bahia. A coleta foi realizada em 30 caprinos com granuloma e 30 caprinos sem granuloma e sem histórico clínico da doença.

\section{ELISA indireto}

\section{Preparação do antígeno BMD}

Foi utilizada uma linhagem de Corynebacterium psendotuberculosis fornecida pelo laboratório de Microbiologia da Universidade Federal da Bahia, denominada de T1. O cultivo da cepa em caldo BHI foi utilizado para causar expansão em $200 \mathrm{ml}$ de caldo BHI, colocado em estufa a $37^{\circ} \mathrm{C}$, durante 48 horas.

Após esse período, o cultivo foi analisado quanto à sua pureza, aliquotado no fluxo laminar em tubos de ensaio de $10 \mathrm{ml}$ e centrifugado durante 30 minutos a $4000 \mathrm{rpm}$. O sobrenadante foi eliminado e a mass a celular foi ressuspendida em $10 \mathrm{ml}$ de PBS estéril. A suspensão resultante foi agitada e aquecida em banho-maria a $80^{\circ} \mathrm{C}$, durante 2 horas, agitando-se em intervalos aproximados de 15 minutos. Após o resfriamento, a suspensão celular foi centrifugada a $4000 \mathrm{rpm}$, durante 10 minutos, para eliminar as macropartículas e restos celulares. O líquido sobrenadante, que constitui o antígeno, foi recolhido e congelado durante 48 horas à temperatura de $-20^{\circ} \mathrm{C}$, e os sedimentos foram descartados. $\mathrm{O}$ antígeno foi descongelado e centrifugado a $4000 \mathrm{rpm}$, durante 10 minutos, para eliminar os lipídeos. O sedimento foi eliminado e o sobrenadante congelado novamente, o qual foi dialisado a uma temperatura de $4^{\circ} \mathrm{C}$, durante 3 dias, com PBS, sendo a solução trocada a cada 8 horas.

\section{Ensaio imunoenzimático indireto (ELISA i) com antígeno BMD}

As placas de poliestireno de fundo chato (marca COSTAR 3590) foram sensibilizadas com 100 ul do antígeno BMD, diluído a 1:100, em tampão carbonato- bicarbonato 0,05M, pH 9,6, incubadas a $4^{\circ} \mathrm{C}$, por aproximadamente 18 horas. Após duas lavagens com PBS, contendo $0,1 \%$ de tween-20, as placas foram bloqueadas com $200 \mathrm{ul} /$ poço de PBS-T20, contendo 5\% de leite desnatado (Molico), durante duas horas. A seguir, foram incubadas com $50 \mathrm{ul} /$ poço dos soros testes diluídos a 1:100 em PBS-T-20, contendo $0,5 \%$ de BSA (soro fetal bovino), durante 1 hora. Após 5 lavagens em PBS-T-20, adicionouse às placas 50 ul de imunoglobulinas de coelho, anti-imunoglobulina de caprino, conjugada à peroxidase (DAKO), diluída a 1:10.000 em PBS-T-20. As placas foram incubadas a $37^{\circ} \mathrm{C}$, por 45 minutos e, em seguida, lavadas novamente cinco vezes em PBS-T-20 e incubadas com 50 ul poço da solução reveladora (10 ml de tampão cítrico-fosfato pH 5,1 + ortofenilenodiamina $4 \mathrm{mg}+4 \mathrm{ul} \mathrm{H}_{2} \mathrm{0}_{2}$ ), freando a reação com 25 ul do ácido sulfúrico $\left(\mathrm{H}_{2} \mathrm{SO}_{4}\right)$ 4N. A leitura foi realizada em leitor de ELISA, usando-se filtro de 490 nm de comprimento de luz.

\section{Preparação do antígeno BHI}

O protocolo de produção deste antígeno foi realizado segundo Carminati et al. (2003), utilizando-se uma linhagem de Corynebacterium psendotuberculosis do laboratório de Microbiologia, da Universidade Federal da Bahia. O cultivo da cepa em caldo BHI foi utilizado para causar expansão em 200 $\mathrm{ml}$ de caldo $\mathrm{BHI}$, colocado em estufa $37^{\circ} \mathrm{C} / 48$ horas. Após esse período, o cultivo foi analisado quanto à sua pureza, aliquotado no fluxo laminar em tubos de ensaio de $10 \mathrm{ml}$ e centrifugado durante 30 minutos a $4000 \mathrm{rpm}$. O sobrenadante foi filtrado e o líquido sobrenadante, que constitui o antígeno, foi recolhido e congelado à temperatura de $-20^{\circ} \mathrm{C}$. 


\section{Ensaio imunoenzimático indireto (ELISA i) com antígeno BHI}

As placas de poliestireno de fundo chato (marca COSTAR 3590) foram sensibilizadas com 100 ul do antígeno BHI, diluído a 1:100, em tampão carbonato bicarbonato 0,05M, pH 9,6, incubadas a $4^{\circ} \mathrm{C}$, por 12 horas. Após duas lavagens com PBS (0,1\% de tween-20), as placas foram bloqueadas com 200 ul/poço de PBS-T20 (5\% de leite desnatado (Molico)), durante duas horas. A seguir, foram incubadas com $50 \mathrm{ul} /$ poço dos soros testes diluídos a 1:100 em PBS-T-20, contendo 0,5\% de BSA (Soro Fetal Bovino), durante uma hora. Após 5 lavagens em PBS-T-20, adicionou-se às placas 50 ul de imunoglobulinas de coelho, anti-imunoglobulina de caprino, conjugada à peroxidase (DAKO), diluída a 1:10.000 em PBS-T20. As placas foram incubadas a $37^{\circ} \mathrm{C}$, por 45 minutos e, em seguida, lavada novamente cinco vezes em PBS-T-20 e incubadas com $50 \mathrm{ul} /$ poço da solução reveladora $(10 \mathrm{ml}$ de tampão cítrico-fosfato pH 5,1 + ortofenilenodiamina $\left.4 \mathrm{mg}+4 \mathrm{ul} \mathrm{H}_{2} \mathrm{O}_{2}\right)$, interrompendo a reação com 25 ul de ácido sulfúrico $\left(\mathrm{H}_{2} \mathrm{SO}_{4}\right) 4 \mathrm{~N}$. A leitura foi realizada em leitor de ELISA, usando-se filtro de $490 \mathrm{~nm}$ de comprimento de luz.

\section{RESULTADOS}

Os valores de absorbância obtidos com o teste ELISA indireto, utilizando o antígeno BMD, nas amostras de soros caprinos, que apresentavam sintomatologia clínica para a linfadenite caseosa, variaram aproximadamente entre 0, 250 e 1,8. Nas amostras de soros caprinos, que não apresentaram sintomatologia clínica para a doença, utilizando o mesmo antígeno nas amostras positivas, verificaramse valores de absorbância variáveis, aproximadamente entre 0,1 a 0,3. Esses resultados podem ser observados nas Figuras 1 e 2.

\section{ELISA INDIRETO - Ag BMD}

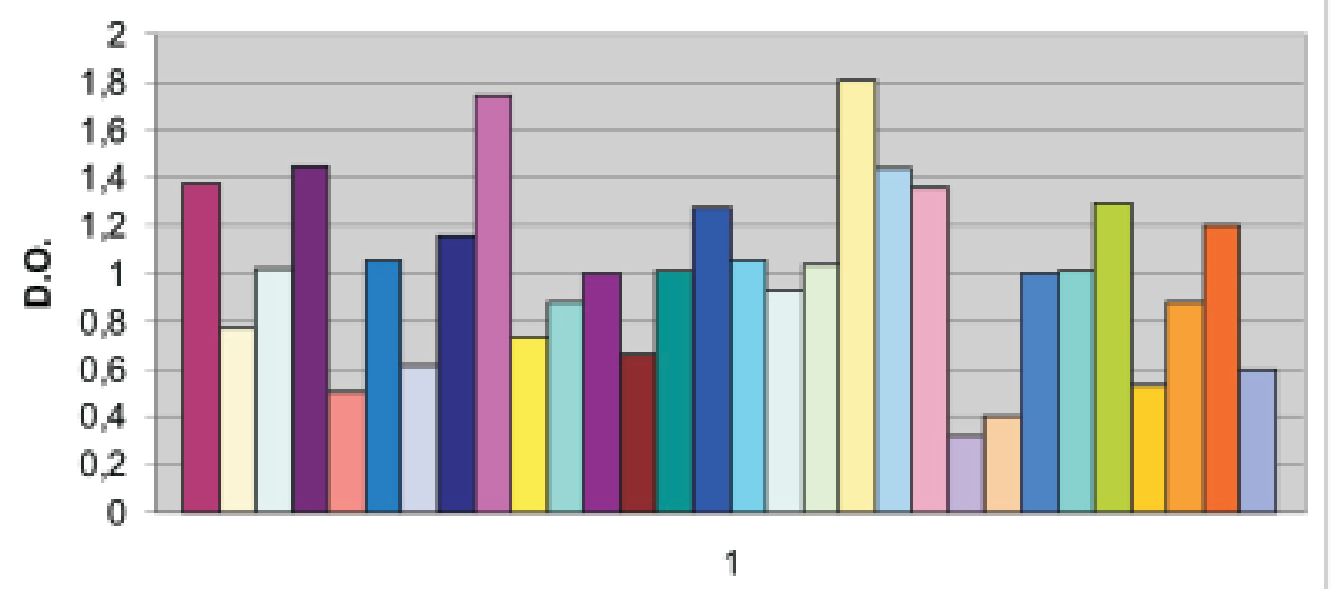

Amostras de soros positivos

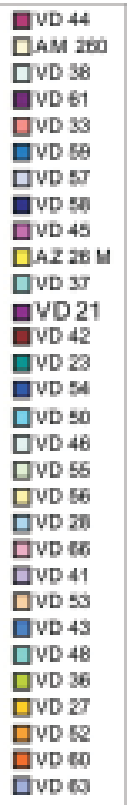

FIGURA 1 - Absorbância de soros de caprinos naturalmente infectados com C.pseudotubercusis Figure 1 - Absorbance of serum goats naturally infected with C. pseudotuberculosis 


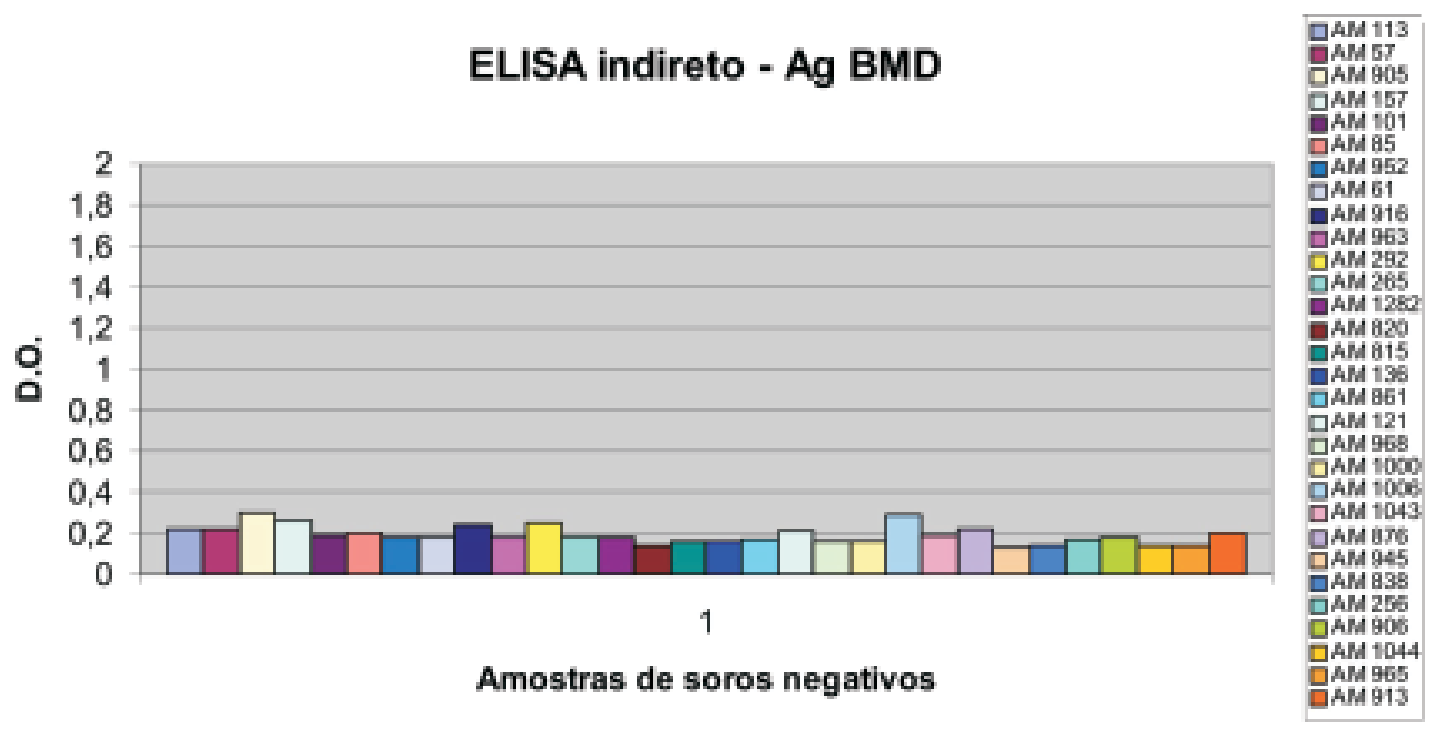

FIGURA 2 - Absorbância de soros de caprinos não infectados com C. pseudotuberculosis Figure 2 - Absorbance of serum goats not infected with C. pseudotuberculosis

Em contrapartida, no teste ELISA indireto, utilizando o antígeno BHI já padronizado e descrito na literatura para comparação com o antígeno BMD preparado no LADI, obtiveram-se valores de D.O. nas amostras de caprinos com sintomatologia clínica para linfadenite caseosa com variação entre 0,3 a 1,7. Os valores da absorbância nas amostras de soros negativos para a doença oscilaram entre 0,1 e 0,3. Resultados como esses comprovam a eficácia dos dois antígenos utilizados para os testes ELISA indireto e podem ser observados nas Figuras 3 e 4.

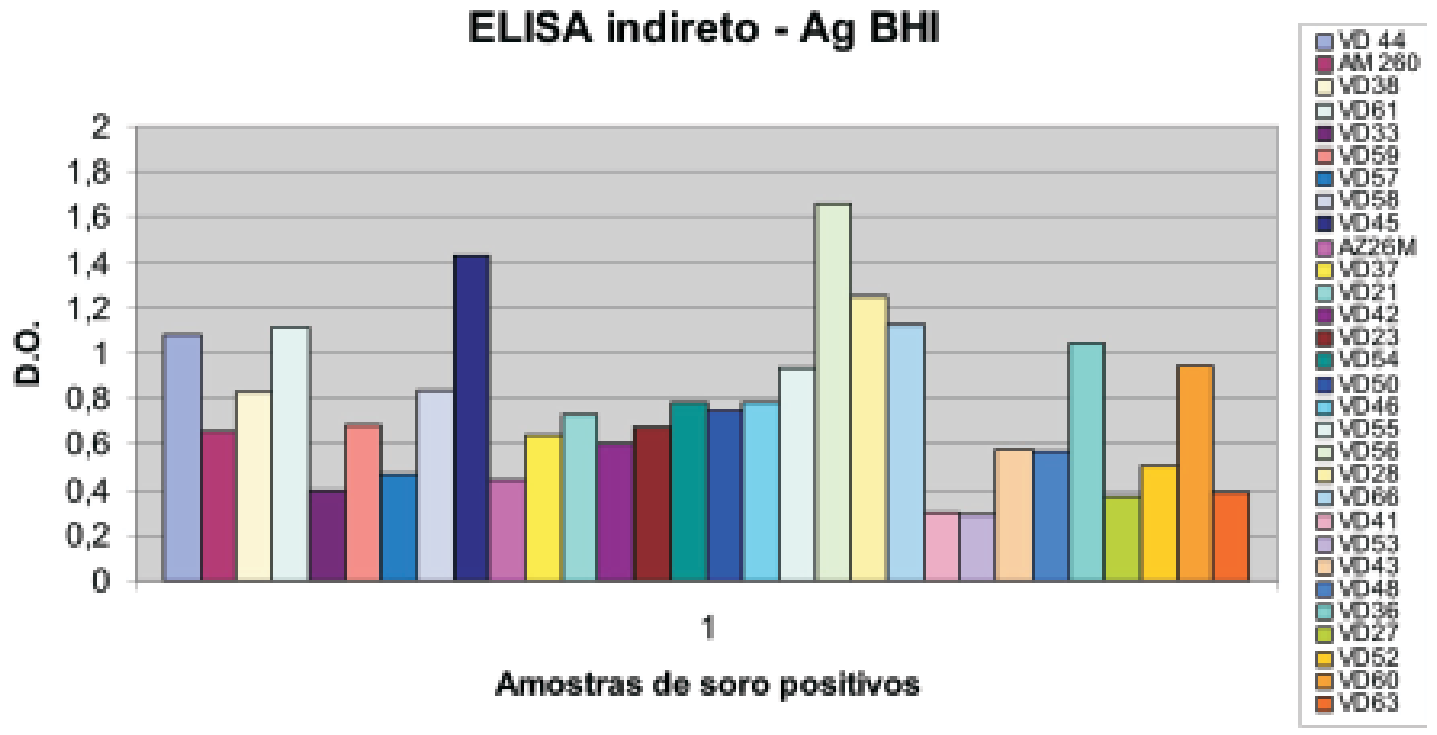

FIGURA 3 - Absorbância de soros de caprinos naturalmente infectados com C.psendotubercusis Figure 3 - Absorbance of serum goats naturally infected with C. pseudotuberculosis 


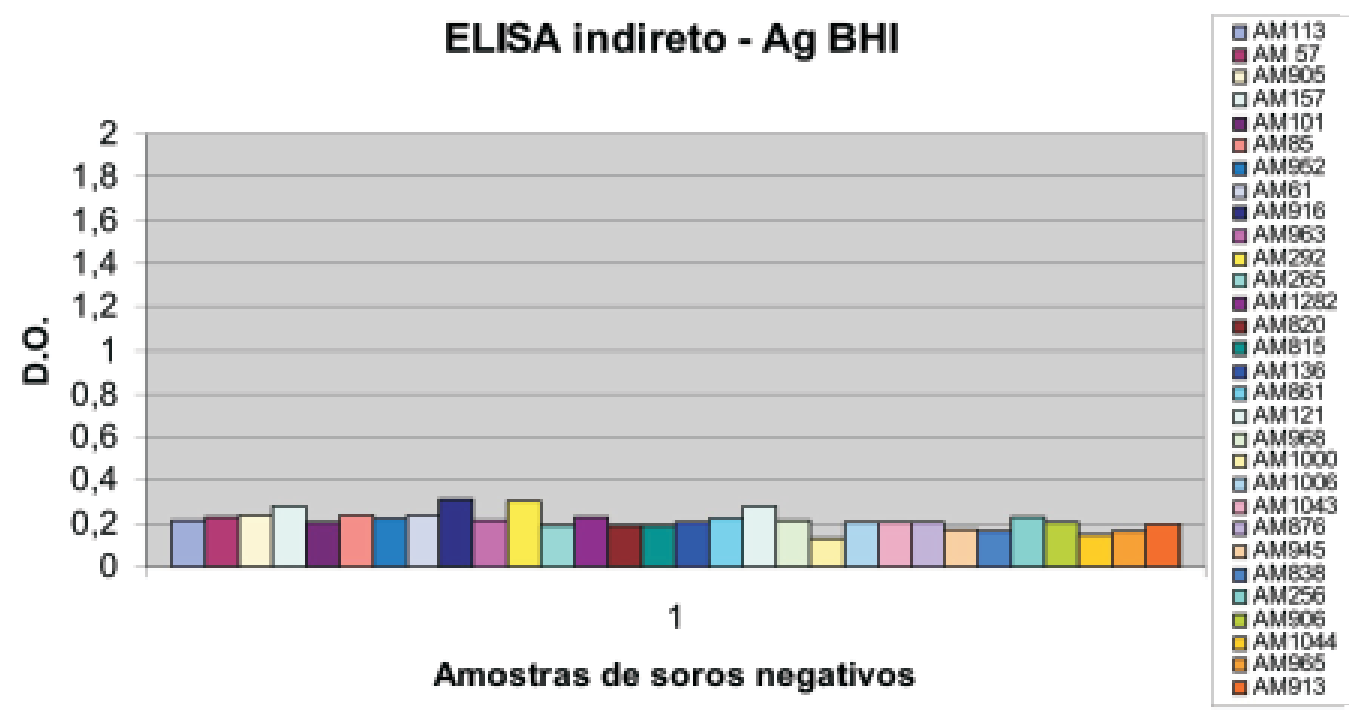

FIGURA 4 - Absorbância de soros de caprinos não infectados com C.psendotuberculosis

Figure 4 - Absorbance of serum goats not infected with C. pseudotuberculosis

\section{Definição dos pontos de corte dos testes ELISA indireto}

O cut-off foi definido por meio da curva ROC, a qual tem a finalidade de avaliar a sensibilidade em função da especificidade. É importante ressaltar que a região delimitada pela curva do teste ELISA indireto BMD foi mais expressiva, quando comparado ao ELISA indireto com antígeno BHI.

$\mathrm{Na}$ Tabela 1 estão apresentados os valores de sensibilidade e especificidade dos testes ELISA, conforme os seus respectivos pontos de corte. Na Tabela 2 podem ser verificados os valores preditivos e negativos de cada um dos testes.

TABELA 1 - Valores de sensibilidade, especificidade e cut-off Table 1 - Value of sensitive, specifity and cut-off

\begin{tabular}{lccc}
\hline Sensibilidade/Especificidade & Sensibilidade (\%) & Especificidade (\%) & Cut-off \\
EL.ISA & & & \\
\hline ELISA BHI & 98,0 & 98,0 & 0,248 \\
ELISA BMD & 99,8 & 98,0 & 0,310 \\
\hline
\end{tabular}

TABELA 2 - Valores preditivos de amostras positivas e negativas Table 2 - Prediction values of positive and negative samples

\begin{tabular}{lcc}
\hline ELISA indireto & $\begin{array}{c}\text { Valor Preditivo Amostras Positivas } \\
(\%)\end{array}$ & \begin{tabular}{c} 
Valor Preditivo Amostras Negativas (\%) \\
\hline $\begin{array}{l}\text { ELISA indireto } \\
\text { com antigeno BHI }\end{array}$
\end{tabular} \\
$\begin{array}{l}\text { ELISA indireto } \\
\text { com antigeno } \\
\text { BMD }\end{array}$ & 98 & 98 \\
\hline
\end{tabular}




\section{Comparação entre os testes ELISA indireto}

A comparação entre o ELISA indireto com antígeno BMD e o ELISA indireto com antígeno BHI foi realizada pelo coeficiente de correlação de Pearson, onde obteve-se um valor de 0,842, conforme a Tabela 3. O índice Kappa, verificado entre os testes ELISA indireto, apresentaram concordância quase perfeita para um valor 0,96 , observado na Tabela 4 .

TABELA 3 - Valores de Coeficiente de Correlação de Pearson Table 3 - Pearson Correlation coefficient V alue

\begin{tabular}{lc}
\hline ELISA indireto & Coeficiente de Pearson \\
\hline $\begin{array}{c}\text { ELLISA BHI X EL.ISA } \\
\text { BMD }\end{array}$ & 0,842 \\
\hline
\end{tabular}

TABELA 4 - Valores do Coeficiente de Correlação de Pearson pelo índice Kappa Table 4 - Pearson Correlation Coefficient Value through Kappa index

\begin{tabular}{cc}
\hline ELLISA indireto & Coeficiente de Correlação Pearson Através do Indice Kappa \\
\hline $\begin{array}{c}\text { ELISA BHI X ELISA } \\
\text { BMD }\end{array}$ & 0,96 \\
\hline
\end{tabular}

\section{DISCUSSÃO}

Autores têm demonstrado que as proteínas encontradas no sobrenadante da cultura de $C$. pseudotuberculosis em caldo BHI e reconhecidas por western blotting têm peso molecular abaixo de 68 KDa (ELLIS et al., 1991; MUCKLE et al., 1992; BRAITHWAITE et al., 1993). A extração de proteínas ligadas à superfície da célula bacteriana, mediante lavagem com cloreto de sódio, identificaram uma banda de $120 \mathrm{KDa}$, reconhecida por todos os soros de caprinos e ovinos infectados (MUCKLE et al., 1992). Braithwaite et al. (1993) identificaram que a extração de antígenos ligados à superfície da célula, por meio do uso do detergente SDS, revelou bandas protéicas de 20 a 119 KDa, reconhecidas pelo soro de caprinos infectados. Esses antígenos extraídos da superfície da bactéria foram considerados como antígenos somáticos. No presente trabalho, verificou-se que, apesar de não se realizar a determinação da fração protéica, o antígeno utilizado apresentou uma resposta, diferenciando animais infectados de não infectados.

Andersen et al. (1991) demonstraram que o crescimento de $M$. tuberculosis resulta em liberação de proteínas excretadas no meio, ativamente liberadas, nos primeiros dias da cultura. Posteriormente, são liberadas proteínas secretadas que atravessam a membrana citoplasmática e se localizam externamente à parede celular, sendo liberadas gradualmente durante o crescimento bacteriano. Esses resultados são concordantes com os obtidos neste experimento, acreditando-se que a forma de obtenção do antígeno para C. pseudotuberculosis tenha passado pelo mesmo processo. Kaufmann e Hess (1999) sugeriram que antígenos secretados de $M$. tuberculosis seriam mais eficazes que os antígenos somáticos para compor uma vacina e para utilização em testes diagnósticos para estas bactérias.

A sensibilidade e a especificidade são parâmetros fundamentais para a definição de um teste diagnóstico. A sensibilidade pode ser definida como a probabilidade do teste ser positivo, caso o animal esteja doente, enquanto especificidade seria a probabilidade de o teste ser negativo no animal não doente (XU; LOHR; GREINER, 1997). 
Juliano Zerbinati et al.

Segundo Carminati et al. (2003), utilizando como antígeno o secretado de cultura de 48 horas de crescimento de Corynebacterium pseudotuberculosis em caldo BHI para um teste ELISA indireto desenvolvido e padronizado para o diagnóstico da linfadenite caseosa em caprinos, obtiveram sensibilidade de 93,5\% e 100\% de especificidade, mostrando ser um teste capaz de afastar animais que se mostrem falso positivo. Resultados distintos foram obtidos no presente trabalho, onde se obteve sensibilidade de 99,8\% e especificidade de $98 \%$ para o ELISA indireto com antígeno BMD e sensibilidade e especificidade de $98 \%$ para o ELISA com antígeno BHI.

Dercksen et al. (2000), trabalhando com soros caprinos para um teste ELISA indireto do tipo "sanduíche", no qual utilizou como antígeno a exotoxina da bactéria, obtiveram sensibilidade de $94+3 \%$ e especificidade de $98+1 \%$. No presente estudo, verificaram-se resultados discordantes com relação à sensibilidade (maior) e concordante em relação à especificidade, decorrente da forma de obtenção dos antígenos utilizados.

Moura Costa et al. (2002) desenvolveram um meio sintético para possibilitar o crescimento do Corynebacterium pseudotuberculosis ausente de proteínas exógenas, permitindo a produção de proteínas secretadas pela bactéria. Esse complexo antigênico foi utilizado para padronização de um teste ELISA indireto no diagnóstico da doença em caprinos e possibilitou detectar sensibilidade de 96,8\% e especificidade $98,2 \%$. Os resultados identificados são discordantes dos obtidos no presente experimento, onde se detectou uma sensibilidade de $99,8 \%$ e uma especificidade próxima à verificada, de $98 \%$ para 0 ELISA com antígeno BMD.

No presente trabalho, constatou-se que o ELISA com antígeno BMD possui uma capacidade maior de discriminar os grupos infectados do grupo não infectado, concordando com os resultados obtidos por Carminati (2005), que trabalhou com um antígeno denominado de TPP. Verificou-se também uma diferença no teste ELISA BHI entre os grupos infectados e não infectado.

\section{CONCLUSÕES}

A sensibilidade e a especificidade do teste ELISA indireto, utilizando o antígeno BMD, foram de $99,8 \%$ e 98,0\%, respectivamente, onde a sensibilidade foi maior e a especificidade foi igual, ao comparar com teste ELISA indireto utilizando o antígeno BHI.

Constatou-se que o teste ELISA indireto, utilizando o antígeno BMD, apresenta maior capacidade de discriminação entre os animais com a doença e sem a doença em relação ao teste ELISA indireto, utilizando o antígeno BHI.

\section{REFERÊNCIAS}

ANDERSEN, P. et al. Proteins Released from Mycobacterium tuberculosis during Growth. Infectious Immunological, v. 59, n. 6, p. 1905 -1910, 1991.

AYERS, J. L. Caseous lymphadenitis in goats and sheep: a preview of diagnosis, pathogenesis, and immunity. JAVMA, v. 171, n. 12, p. 1251-1254, 1977.

BRAITHWAITE, C. M. et al. Characterization of detergent-soluble proteins of Corynebacterium pseudotuberculosis. Veterinary Microbiology. v. 38, p. 59-70, 1993.

CAMERON, C. M.; MINNAAR, J. L. Immunization of mice against Corynebacterium pseudotuberculosis infection. Veterinary Research Institute, Onderstepoort, v. 2, n. 36, p. 207-210, 1969.

CAMERON, C. M.; FULS, W. J. P. Studies on the enhancement of immunity to Corynebacterium psendotuberculosis. Onderspoort Journal Veterinary Research, v. 40, n. 3, p. 105-114, 1973. 
CARMINATI, R. Estudo da sensibilidade e especificidade de quatro testes ELISA e utilização da técnica de PCR para o diagnóstico de linfadenite caseosa em caprinos. 2005. 76 f. Dissertação (Mestrado em Imunologia) - Instituto de Ciências da Saúde, Universidade Federal da Bahia, Salvador, 2005.

CARMINATI, R. et al. Determinação da sensibilidade e da especificidade de um teste ELISA indireto para o diagnóstico de linfadenite caseosa em caprinos, Revista Ciências Médicas Biológicas. Salvador, v. 2, n. 1, p. 88-93, jan./jun. 2003.

DERCKSEN, D. P. et al. Comparison of four serological tests for the diagnosis of caseous lymphadenitis in sheep and goats, Veterinary Microbiology, v. 2, n. 75, p. 167-175, 2000.

ELLIS, J. A. et al. Antigen specificity of antibody responses to Corynebacterium pseudotuberculosis in naturally infected sheep with caseous lymphadenitis. Veterinary Immunology Immunopathological, v. 1, n. 28, p. 289-301, 1991.

KAUFMANN, S. H. E.; HESS, J. Impact of intracellular of and antigen display by intracellular bacteria: implication for vaccine development. Immunology, v. 65, n. 1, p. 81-84. 1999.

MOURA COSTA, L. F. et al. Meio sintético quimicamente definido para o cultivo de Corynebacterium psendotuberculosis. Revista Brasileira Saúde Produção Animal, v. 1, n. 3, p. 1-9, 2002.

MUCKLE, C. A. et al. Analysis of the immunodominant antigens of Corynebacterium pseudotuberculosis. Veterinary Microbiology, v. 30, p. 47-58, 1992.

NOZAKI, C. N.; FARIA, M. A. R.; MACHADO, T. M. M. Extirpação cirúrgica dos abscessos da linfadenite caseosa em caprinos. Arquivo Instituto Biológico, v. 67, n. 2, p. 187-189, 2000.

XU, H.; LOHR, J.; GREINER, M. The selection of ELISA cut-off points for testing antibody to Newcastle disease by two-graph receiver operating characteristic (TG-ROC) analysis. Journal Immunology Methods, v. 208, p. 61-64, 1997.

Recebido em: 27/10/2006

Received in: 10/27/2006

Aprovado em: 30/03/2007

Approved in: 03/30/2007 